\title{
Functionalization Methods of Carbon Nanotubes and its Applications
}

\author{
Lifei Chen, Huaqing Xie and Wei Yu \\ School of Urban Development and Environmental Engineering, \\ Shanghai Second Polytechnic University, \\ Shanghai, \\ China
}

\section{Introduction}

In 1991 Iijima [Iijima, 1991] presented transmission electron microscopy observations of elongated and concentric layered microtubules made of carbon atoms, nowadays which were called carbon nanotubes (CNTs). In order to understand the structure of a carbon nanotube, it can be first imagined as a rolled up sheet of graphene with planar-hexagonal arrangement of carbon atoms distributed in a honeycomb lattice. CNTs are classified into single-walled carbon nanotube, double-walled carbon nanotube, and multi-walled carbon nanotube according to the rolling layers of graphene sheets. Several techniques for producing CNTs have been established and all of them have advantages as well as disadvantages. Usually being applied methods are high temperature techniques, namely arc discharge [Bystrzejewski et al., 2008; Sun et al., 2007] and laser ablation [Rüummeli et al., 2007], as well as chemical vapor deposition (CVD) with its most common variants [Ayala et al., 2008; Nikolaev et al., 1999]. CNTs possess unique electronic, chemical, and mechanical properties that make them leading materials for a variety of potential applications. But the outer wall of pristine CNTs is, in principle, conceived as chemically inert. This is not always desirable for applications and for this reason. One of the most promising routes to overcome this difficulty is to functionalize CNT. Functionalization extends their properties and consequently their application potential. Hence understanding their functionalization is crucial for fully exploiting their potential. Researchers have developed some effective methods to functionalize CNT surfaces such as covalent modification or noncovalent approaches including polymer wrapping, biomolecule binding, and metal ion binding. Other functionalization routes which have been thought to make them chemically active in the past few years, including chemical and solid-phase or hydro-mechanochemical method will also be introuduced in details in the following contributions. The advantages and shortcomings of every functionalization method will be showed clearly. At the same time some characterization methods for CNTs will be also refered. In the last part of this chapter the applications of carbon nanotubes as functional materials in the fields of biosensing, fuel cells, medical treatment, and so on, especially in the field of thermal conductivity are summarized. It is our hope that all the content of this chapter can supply helps to the researchers in the study of carbon nanotubes. 


\section{Functionalization}

\subsection{Noncovalent functionalization of carbon nanotubes}

CNTs are usually functionalized by harsh oxidative processes, such as refluxing in the mixture of $\mathrm{HNO}_{3}$ and $\mathrm{H}_{2} \mathrm{SO}_{4}$ to generate defects on the sidewalls and tube tips, those defects can serve as anchor groups for functionalization and/or can provide sites for the coordination chemistry [Li et al., 2007]. However, such oxidation method usually reduces the electrical conductivity and corrosion resistance of CNTs due to the introduction of a large number of defects. Therefore, development of a better and more effective functionalization method that can not only introduce high density and homogeneous surface functional groups but also has little or no structural damage to CNTs remains a major challenge. Recently, noncovalent functionalization of CNTs has attracted particular attention because it does not induce any structural transformation and secondary structure.

\subsubsection{Polymer functionalization of multi-walled carbon nanotubes}

Polyaniline, polypyrrole, polythiophene and their derivatives have been considered as promising materials for supercapacitors [Woo et al., 2008], electrochemical sensor [Waghuley et al., 2008], modification agent [Mohana Reddy et al., 2009] and so on due to the existence of various oxidation structures, electrically conducting polymers. Among them, conducting polypyrrole has been the focus of a great deal of research for catalytic materials application in recent years because its superior properties including high electric conductivity, high specific capacitance and good chemical and thermal stability, especially facile synthesis and environmentally friendly. Zhao et al [Zhao et al., 2010] reported a simple chemical polymerization of pyrrole monomer on Multi-walled CNTs (MWNTs) without addition any oxidants at room temperature. This method avoids the requirement of lower temperature and the introduction of lots of impurity ions from the oxidants used during the chemical oxidative polymerization of the pyrrole monomer. Furthermore, such treatment could preserve the integrity and the electronic structure of MWNTs.

Poly ethylene glycol (PEG) have been one of the most preferred synthetic molecular species for various purposes in bio-related applications owing to its non-toxicity as well as its good solubility under various physiological conditions. From many earlier studies Lee et al [Lee et al., 2007] found that molecules containing aromatic moieties are adsorbed onto the graphite surface more strongly than molecules composed only of aliphatic components, owing to $\Pi-\pi$ interaction between the graphite surface and the aromatic component of amphiphilic molecule involving both the van der Waals interaction and the electrostatic interaction. Using amphiphilic molecules to functionalize CNT surfaces has been recognized as one of the most useful approaches to improve the dispersion of CNTs in aqueous media. Using this approach, the solubility of CNTs can be greatly enhanced by anchoring hydrophobic segments on the surfaces of CNTs, where hydrophilic segments are orientated toward the aqueous phase. Recently, several groups reported on the solubilization of singlewalled CNTs (SWNTs) in water using amphiphilic building blocks such as block copolymers, lipids, and surfactants [Balavoine et al., 1999]. Park [Park et al., 2007] described a noncovalent process for surface functionalization of SWNTs using amphiphilic diblock copolymer (PEtOz-PCL), consisting of hydrophilic PEtOz and hydrophobic PCL, with remarkably enhanced solubility particularly in aqueous media. The PEtOz block on the nanotube surface provides possibility to further controlled assembly and also can be utilized as a template for the formation of Au nanoparticles on the surface of SWNT. 
Using polymer chains to 'wrap' CNTs is a versatile and effective way for CNT functionalization. In particular, block copolymers (BCPs) may provide a series of attractive noncovalent wrapping and decoration for the functionalization of CNTs. These approaches can be driven by distinct interactions between CNTs and polymers including p-stacking, electrostatic interactions, and decoration of CNTs with micelles [Zou et al., 2008; Kang et al., 2003]. One block of the BCPs forms a close interaction with CNTs, while the other block(s) provide the dispersibility and chemical compatibility to the CNTs [Szleifer \&YerushalmiRozen, 2005]. More attractively, the intriguing ability of BCPs to self-assemble into ordered nanostructures brings researchers an ideal nanoscale template for CNT alignment control, and can be utilized further for fabrication of functional hybrid materials and functional devices including flexible field emission display panels. Recently, Li et al [Li et al., 2005; Li et al., 2006] decorated CNTs using controlled crystallization of homopolymers such as poly(ethylene) (PE) and nylon-66. The heteroepitaxial growth of crystalline polymers on CNT surfaces provides a new way in noncovalent methods for Wang et al [Wang et al., 2010] to decorate BCP on CNTs via a controlled polymer crystallization method. This method not only provides a noncovalent technique for $\mathrm{BCP}$ decoration on $\mathrm{CNT}$ surfaces, but also provides a promising approach to the uniform dispersion of CNTs in selective microdomains of BCPs and controlled alignment of CNTs in BCP ordered nanostructures. Sluzarenko et al [Sluzarenko et al., 2006] presented a versatile method for the preparation of dispersed nanotubes using polystyrene-b-polyisoprene diblock copolymers in different selective organic solvents. Stable dispersions have been obtained in polar (DMF) and nonpolar (heptane) media depending on the selectivity of the diblock copolymers. The direct interaction between the nanotubes and the different blocks is not the most important parameter for stabilization. The driving force seems to be the selectivity of the solvent toward the block copolymer and the block copolymer ratio. Zhang [Zhang et al., 2006] have investigated the effect of melt mixing on the interaction between multi-walled carbon nanotubes (MWNTs) and polystyrene (PS) matrix. They found that the interaction between pristine MWNTs and PS in solution was exist but not strong enough to allow MWNTs to be soluble in solvent.

Among the noncovalent functionalization, due to absence of reactive groups in the functionalized CNTs, the interfacial interaction between CNTs and epoxy is weak. Li [Li et al., 2008] reported the non-covalent functionalization of MWNTs by using 2- aminoethanol $\left(\mathrm{H}_{2} \mathrm{NCH}_{2} \mathrm{CH}_{2} \mathrm{OH}\right)$ in the presence of sodium hydroxide and the application for conductive composites with higher conductivity. The introduced amine group is expected to react with epoxide group from epoxy prepolymer to improve the interfacial interaction between MWNTs and epoxy matrix leading to efficient MWNTs dispersion.

Good solubility of inherently insoluble CNTs in organic solvents has been achieved through surface modification with various homopolymers and/or block copolymers, either covalently such as surface-targeted grafting or in situ polymerization, or noncovalently. Liu et al [Liu et al., 2006] reported on a simple, nondestructive method to noncovalently modify MWNTs with a graft polymer synthesized in laboratory, polystyrene-g-(glycidyl methacrylate-co-styrene) (PS-g-(GMA-co-St)). The noncovalent modification strategy is based on the affinity of the PS main chains to the surfaces of pristine MWNTs (p-MWNTs), and the modified MWNTs can be solubilized in a wide variety of polar and nonpolar organic solvents at the same time. 


\subsubsection{Aromatic small-molecule-based noncovalent functionalization}

The traditional noncovalent methods usually suffer from some disadvantages, such as the low loadings in solutions, the specific complex and synthetic reagents for the functionalization, and a long period of sonication. Hu [Hu et al., 2006] et al presented a new noncovalent approach for the dissolution and the surface modification of SWNTs by a commercially available diazo dye, Congo red (the molecular structural formula is shown in Fig. 1). The stability of solubilized SWNTs + CR were observed for more than two months, and should be realized by the the $\Pi$-stacking interaction between the sidewall and Congo red.<smiles>Nc1c(N=Nc2ccc(-c3ccc(N=Nc4cc(S(=O)(=O)O)c5ccccc5c4S([O])(=O)=O)cc3)cc2)cc(S(=O)(=O)[O-])c2ccccc12</smiles><smiles>COS(=O)(=O)c1cc2cc(S(=O)(=O)O[Na])cc(N)c2c(O)c1N=Nc1ccc(-c2ccc(N=Nc3c(S(=O)(=O)O[Na])cc4cc(S(=O)(=O)O[Na])cc(N)c4c3O)c(C)c2)cc1C</smiles>

Fig. 1. Molecular structures of Congo red and trypan blue

Among chemical modification, chemical doping and physical treatments, modifying the nanotube surface using aromatic moieties through noncovalent interaction is a very attractive one. Noncovalent functionalization to the CNT not only is a much simpler method compared with covalent functionalization but also has the advantage of preserving nanotube's $\mathrm{sp}^{2}$ structure, thus the electronic properties [Tournus et al., 2005; Lu et al., 2006]. Though noncovalent sidewall functionalization of CNTs using aromatics molecules has shown many exciting potentials, there has been very few systematic studies on their interaction mechanism. Herein, Liu et al [Liu et al., 2008] systematically studied the noncovalent functionalization of MWNTs by using a series of aromatic organic dyes (Scheme 1) with different structural characteristics. These molecules can be classified into three different categories based on their morphologies and also can be classified into three groups according to their loaded charges in protonic solvents. They found that molecular geometry and charge play the key roles for the dye-MWNTs interactions. The molecules with planar structures and high charge load are favored for the adsorption.

Zhang et al [Zhang et al., 2004] studied the functionalization of SWNTs with electroactive inorganic compounds: Prussian blue $(\mathrm{PB})$ and investigated the molecular interactions between them. They also found that $\Pi-\Pi$ stacking interaction coupled with ionic interaction exist between SWNTs and PB. 


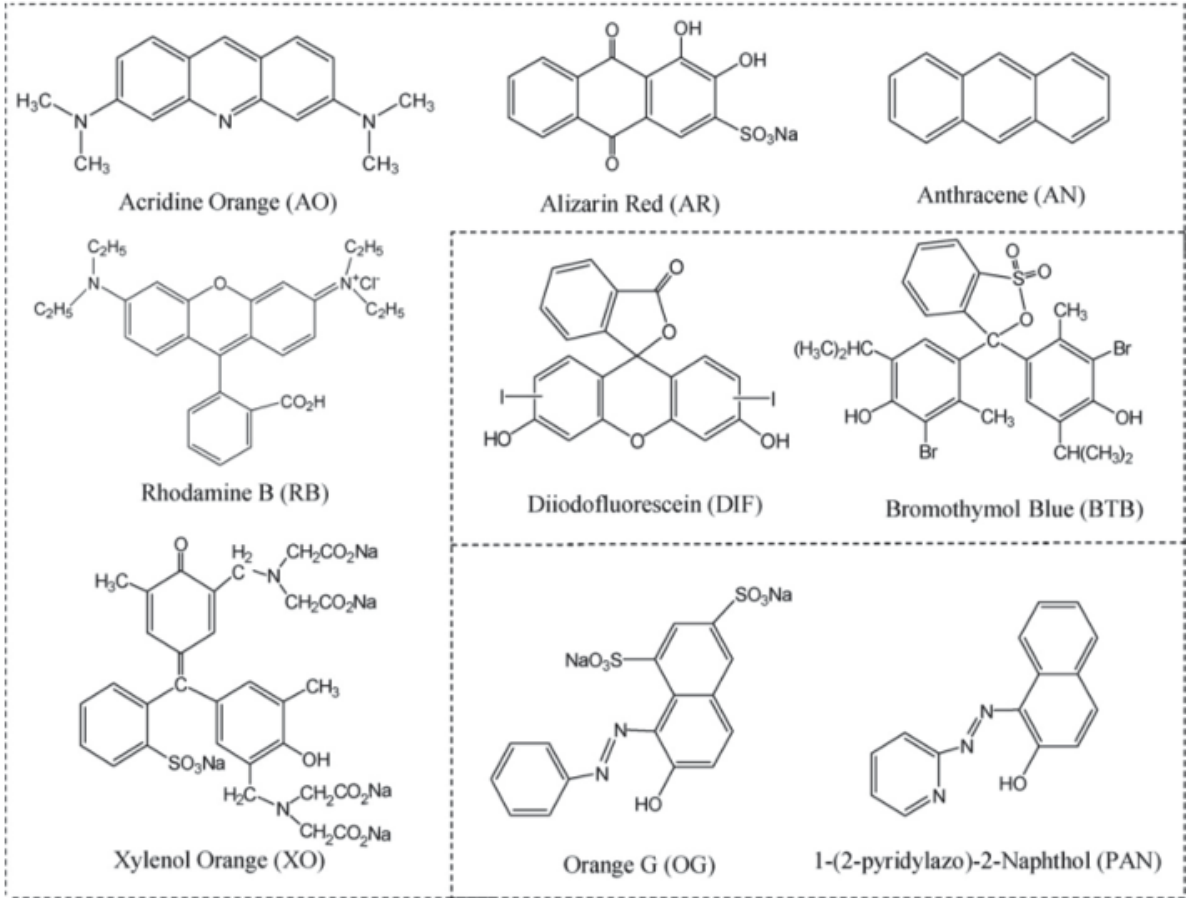

Scheme 1. Structures and names of the used dye molecules

\subsubsection{Bio-molecule-based noncovalent functionalization}

The potential use of CNTs in biorelated areas has prompted many researchers to investigate the functionalisation of CNTs with biological macromolecules such as proteins and oligosaccharide [Baker et al., 2002; Chen et al., 2001]. Noncovalent functionalization of CNTs with bio-macromolecules, such as DNA and proteins is an additional potential strategy to prepare new bioelectronic nanomaterials [Bale et al., 2007; Chen et al., 2001], which could take advantage of the molecular recognition properties of the bound biomolecules. Wei et al. found that a hydrophobic protein called PANHS can be utilized for controlled noncovalent functionalization of MWNTs and at the same time can be used to control the assembly of AuNPs after binding AuNPs onto the proteins [Wei et al., 2010]. They also investigated the formation of MWNT-AuNP hybrids by incubating proteinprotected AuNPs with PANHS functionalized MWNTs, as introduced in Fig 2. They found that proteins, as an intermediate that can react with both MWNTs and AuNPs, play a significant role for mediating the assembly of AuNPs and formation of different hybrids based on MWNTs.

The effectiveness of dispersing and purifying carbon soot using biopolymers (e.g., proteins or DNA) has been studied extensively. Dieckmann et al. [Dieckmann et al., 2003] used nonspecific binding of a-helix amphiphilic peptide to assist in dispersing CNTs in aqueous media. The hydrophobic region of the peptide interacted with the aromatic surface of the CNT, while the hydrophilic face promoted self-assembly through peptide-peptide interactions. Zheng et al. [Zheng et al., 2003] demonstrated that the ssDNA self-assembled 
into a helical structure around individual tubes in such a way that the electrostatics of the DNA-CNT hybrid depends on the tube diameter and electronic properties. Zhong et al [Zhong et al., 2009] applied X-ray absorption near edge structure (XANES) spectroscopy to investigate the adsorption mechanism of streptavidin proteins onto SWNTs and found that due to the presence of a hydrophobic pocket (of proteins) and a hydrophobic surface (of SWNTs), the $\mathrm{C}=\mathrm{O}$ protein bonds are affected by the corresponding aromatic structure of SWNTs and an interface interaction occurs, leading to small but relevant structural distortions.

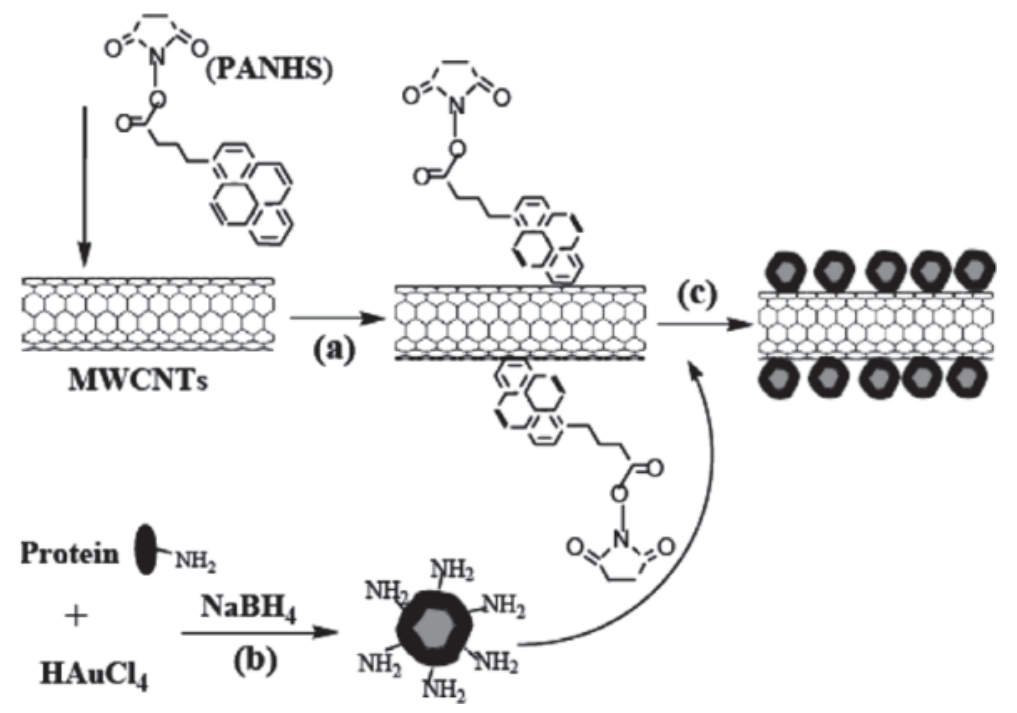

Fig. 2. Model representation for the protein-mediated formation of MWNT-AuNP hybrids. (a) Functionalization of MWNTs with PANHS. (b) Preparation of protein-protected AuNPs.

(c) Self-assembly of protein-protected AuNPs on MWNTs by the nucleophilic substitution of NHS group with primary and secondary amines on the surface of protein.

Xue et al [Xue et al., 2011] previous work focused on functionalized MWNTs with arginineglycine-aspartic acid-serine peptide for cell capture. Dynamic change in the glycosylation status on carcinoma cell surfaces has been considered to play important roles in oncogenic transformation, cell differentiation, and metastasis. Hydrophobins are small proteins $(\sim 100$ amino acids) that play various roles in fungal physiology related to surface phenomena, such as adhesion, formation of surface layers, and lowering of surface tension [van Wetter et al., 2000]. The remarkable property of hydrophobins is that they have both hydrophobic and hydrophilic parts which make them easy to self-assemble at various interfaces to form polymeric amphipathic membranes and effect the reversal of the surfaces wettability. However, in contrast to these surfactants, surface activity depends on a conformational change of the molecules during assembly rather than on a diffusion-limited adsorption to the interface. Utilization of the properties of hydrophobins in applications such as coatings, emulsion stabilization, and separation technologies has been discussed [Hektor \& Scholtmeijer, 2005]. Recently, the ability of hydrophobins to improve the dispersibility of hydrophobic particles in water [Kurppa et al., 2007] has been demonstrated. In addition, the 
protein presents numerous reactive groups such as hydroxyls, amines, thiols, and carboxylic acids which provide sites for further surface modification of the CNTs.

Graphite is composed of layers, which form the infinite extension of the polyacene structure. It shows affinity towards acromatics due to its $2 \mathrm{D}$ structure with conjugated $\pi$ bonds. In addition, incorporation of graphite into the polymer matrix can effectively modify the polymer chain packing. Considering the superior properties such as high flexibility, low mass density, and the effective $\Pi-\pi$ stacking interaction between CNT and aromatic compounds [Zhao et al., 2003], CNT with 1D structure and considerable nanochannels is speculated to be excellent candidate for substituting or complementing conventional nanofillers in the fabrication of nanocomposite pervaporation membranes [Sung et al., 2004; Moniruzzaman et al., 2006]. However, two issues have to be solved in order to fully explore the potential of CNTs. One is the serious aggregation of CNTs leading to difficulties in their manipulation and incorporation into polymeric matrixes [Delozier et al., 2006]. Another is the strong hydrophobicity leading to significant decrease of membrane selectivity. Hydrophilic modification seems a promising and feasible solution. Therefore, chitosan (CS) with distinct hydrophilicity due to the existence of high proportion amino and hydroxyl groups is introduced in Peng et al [Peng et al., 2007] studies. They remarkably improved the dispersion and solubility behavior of CNT through substantial wrapping of chitosan utilizing the emulsifying capacity of chitosan, and the unique solubility behavior of chitosan.

Remarkable properties for biological applications can be obtained due to unique structure of DNA. DNA has been shown to interact with CNTs and wrap onto single-walled carbon nanotubes (SWNTs) for their dispersion and DNA transportation [Lustig et al., 2005; Liu et al., 2007]. DNA-coated carbon nanotube (DNA-CNT) solutions are stable for months at room temperature [Ming et al., 2007]. Many applications for the DNA-CNT system are being explored, including biosensors, DNA transporters, and field effect transistors. The advantages of most of the studies on DNA-stabilized nanotubes have been based on sonication treatment for SWCTs functionalization. According to this, Li [Li et al., 2009] and his coworkers reported a simple method based on sonication treatment to obtain supramolecular adduct of DNAMWNT composites. It is found that DNA is an effective dispersant for MWNTs and that these dispersions are very stable. The products were characterized scanning electron microscopy (SEM) and the result is shown in Fig 3. SEM image showed that MWNTs were dispersed sufficiently and covered entirely with DNA. Raman measurements confirmed that the interaction between DNA and MWNTs was realized by the strong $\Pi-\Pi$ interactions between the backbones of DNA and the surface of carbon nanotubes.

\subsection{Covalent functionalization of carbon nanotubes}

Two main strategies including covalent functionalization of the CNT surface with solvophilic molecules and non-covalent surface coating by amphiphilic molecules such as low molecular weight surfactants and polymeric amphiphiles have been proved to prevent the undesirable inter-tube aggregation in solvent. The former has been recognized as an effective means for solubilization or stable dispersion of CNTs, though often gives rise to a severe disruption of mnetworks of the CNTs, and thereby leads to possible losses in their mechanical and electrical properties of pristine CNTs [Peng \& Cho 2000]. Besides, the covalent functionalization of CNT surface, one of the typical example being the carboxylation of CNTs, usually requires tedious reaction process under strong acidic conditions. These disadvantages are circumvented by utilizing amphiphilic molecules whose solvophobic molecular. 


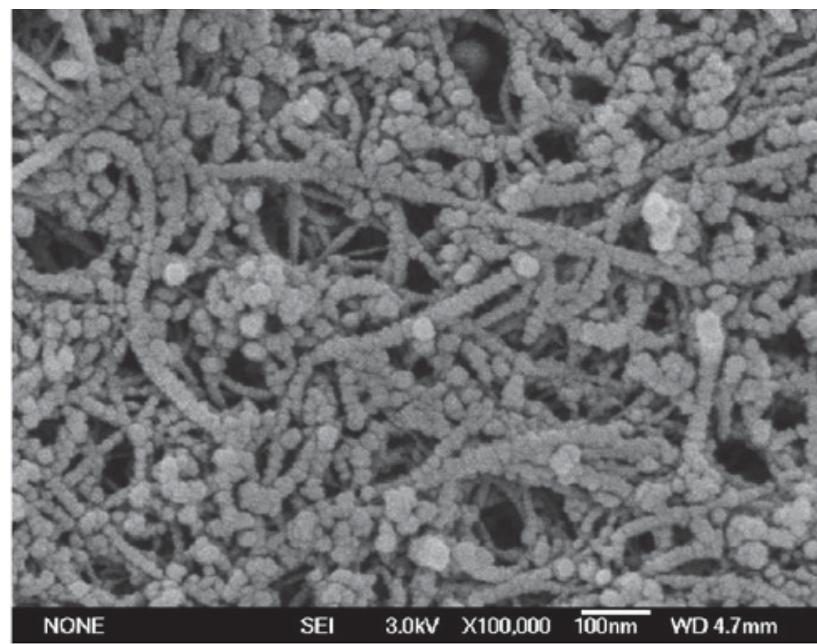

Fig. 3. SEM image of DNA-MWCNT composites with $0.5 \mathrm{wt} \%$ DNA.

It has been proved that the CNTs can cross the cell membranes easily and to deliver the peptides, proteins, nucleic acids, and medical drug into cells [Bianco et al., 2005 \& Wu et al., 2005]. To realize these applications, biomolecules, such as proteins and DNAs, must be bound to CNTs. The biomolecules can be connected to CNTs via noncovalent or covalent bonding. Williams et al.[Williams et al., 2002] developed a method to couple SWNTs covalently to peptide nucleic acid (PNA, an uncharged DNA analogue) and to hybridize these macromolecular wires with complementary DNA. It was found that DNA attachment occurs predominantly at or near the nanotube ends. Maruyama et al.[ Maruyama et al., 2007] reported the attachment of protein molecules to f-MWNTs in an aqueous buffer solution. A chemical reaction using carbodi-imide forms chemical bonds between openended tips of MWNTs and protein molecules. In another study, f-MWNTs were attached to the protein via diimide activated amidation [Huang et al., 2002]. And bovine serum albumin (BSA) proteins can be covalently attached to SWNTs and MWNTs via diimide-activated amidation under ambient conditions, while the overwhelming majority ( $\mathrm{f}=90 \%$ ) of the protein species in the nanotube-BSA conjugates remain bioactive. Hazani et al. [Hazani et al., 2003] have covalently modified SWNTs with DNA and found that the SWNT-DNA adducts hybridize selectively with complementary strands with minimal nonspecific interactions with noncomplementary sequences. Baker et al. [Baker et al., 2002] covalently attached DNA onto SWNTs to develop a DNA biosensor. The good stability, accessibility, and selectivity, however, will be achieved through covalent bonding because of its capability to control the location of the biomolecule, improve stability, accessibility, and selectivity, and reduce leaching. Awasthi et al [Awasthi et al., 2009] reported the preparation of amino f-MWNTs and attachment of biomolecules [e.g. bovine serum albumin (BSA) protein and DNA] to the amino f-MWNTs. The MWNTs have been prepared by spray pyrolysis method and then functionalized with amino group.

Yang et al [Yang et al., 2010] have provided a green method to functionalize CNTs, which avoided the problems of environmental pollution, equipment corrosion, and health hazard causing by both strong acids and organic solvents. This method was shown in Fig 4 . Initially, hydroxyl groups were covalently attached to the surface of MWNTs by one step 
free radical addition of 4,4'-azobis(4-cyanopentanol) (ACP) in water. Poly( $\varepsilon$-caprolactone)grafted MWNTs (MWNT-g-PCL) was then synthesized by in situ ring-opening polymerization of $\varepsilon$-caprolactone in the presence of MWNT-OH in room temperature ionic liquids (RTILs). The hydroxyl-functionalized CNTs are commonly obtained by three steps in turn [Zeng et al., 2006], including oxidation in strong acids, acylation in thionyl chloride, and esterification in organic solvents. Herein, only a one-step process for MWNT-OH is required to perform in water. More importantly, RTILs may provide environmentally benign "green" alternatives to volatile organic solvents for chemical synthesis due to their low volatility, non-flammability and high thermal stability [Greaves \& Drummond, 2008]. Their works about the functionalization of CNTs using water and RTILs as the reaction media appears relatively facile and green in comparison with the one previously reported in strong acids and organic solvents.
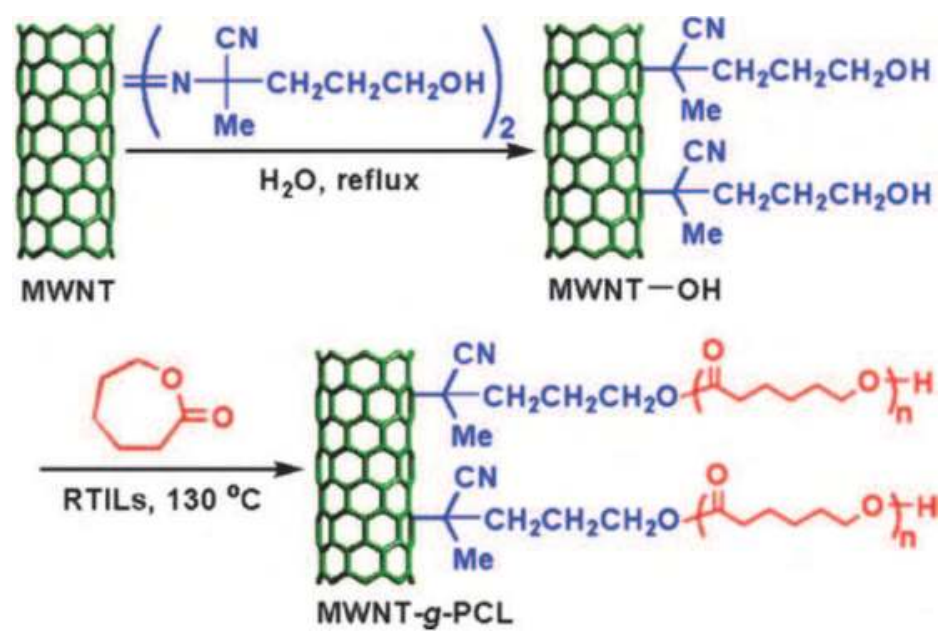

Fig. 4. Schematic representation for covalent attachment of hydroxyl groups to MWNTs by free radical addition of 4,4'-azobis(4-cyanopentanol) in water and subsequent surfaceinitiated ring-opening polymerization of $\varepsilon$-caprolactone in room temperature ionic liquids (RTILs).

Chemical functionalization is an essential prerequisite in order to get uniform properties of the CNT-polymer composites and avoided serious concerns of reproducibility in their electrical, mechanical and thermal behavior caused by segregation and non-uniform mixing behavior. Chemical method is rather easy for their wide use in medical and biological applications since these functional groups provide necessary sites for covalent or noncovalent coupling of SWNTs. Many reactions are required to be carried out over long period of time. For example, for carboxylation or hydroxylation, the reaction mixture is typically refluxed in concentrated $\mathrm{HNO}_{3}$ or acid mixture for $10-50 \mathrm{~h}$, which is a tedious and time consuming process. To avoid this time consuming carboxylation of SWNTs, recently Wang et al. [Wang et al., 2006] have demonstrated a rapid functionalization using microwave (MW) radiation in presence of concentrated acid mixture under pressure.

Conjugated polymers are a novel class of semiconductors, and have been found to have wide applications in many areas, such as organic light emitting diodes for flat panel 
displays, photovoltaic cells for solar energy conversion, thin-film transistors, and chemical sensors [McQuade et al., 2000]. It has arose the researchers great interest to combine the advantages of carbon nanotubes and conjugated polymers. Xu et al [Xu et al., 2007] reported an effective method to prepare the above mentioned novel structure and expected that this kind of novel hybrid structures could be used to fabricate efficient organic solar cells. Through covalent bond connected to the MWNTs, the fluorescence of polyfluorenes was completely quenched by the MWNTs, indicating a fast photo-induced electron transfer from polyfluorenes to MWNTs.

CNTs incorporated inside a matrix have been expected to improve the properties of the polymeric materials including electrical conductivity, mechanical enhancement, and so on. Many strategies to improve their compatibility with a polymer matrix have been provided including surfactant molecules or wrapping polymers which can be used as mixing mediators. Covalent functionalization procedures are sometimes used in order to reduce the interfacial energy between CNT walls and solvent, monomers or polymers. By using this way grafting functional groups on the CNT surface can be chosen to be polymer-compatible, thus increasing the CNTpolymer matrix interactions, though the grafted groups can alterate the CNT structure in the case of high levels of functionalization. Vigolo et al [Vigolo et al., 2009] proposed a multistep procedure to covalently functionalize SWNTs. This chemical procedure is based on the direct attack of the sp2 carbon on the CNT surface through a free radical process. This allows having a certain control of the yield of functionalization without the introduction of a large number of defects. Moreover, $\mathrm{C}-\mathrm{C}$ bond can be created directly on the CNT surface, which is efficient enough to modify the surface properties of the CNTs but preserve their structural integrity, though the yield of functionalization is relatively low.

\subsection{Other functionalization of carbon nanotubes}

One of the methods of chemical surface modification of carbon nanotubes is to use nitric acid $\left(\mathrm{HNO}_{3}\right)$. It also has been performed over distinct carbon materials like activated carbons, carbon xerogels, graphite or ordered mesoporous carbons. The introduction of oxygen-containing groups on the surface of CNTs enhances their solubility in aqueous or organic solvents and reduces the van der Waals interactions between different CNTs, promoting the separation of nanotube bundles into individual tubes. Studies about seeking for the effect of chemical oxidation on SWNT structure, show that functionalization by means of $\mathrm{HNO}_{3}$ causes the tube caps open but basically retain their pristine electronic and mechanical properties. No significant defects are additionally produced, thus the chemical modification mostly occurs at the opened caps and at the already existing defects along the sidewall of SWNTs [Balasubramanian \& Burghard, 2005]. As the $\mathrm{HNO}_{3}$ is used at very high concentrations using boiling methods high density of oxygen-containing groups can be introduced efficiently. Marques et al [Marques et al., 2010] have developed a methodology to tailor the introduction of oxygenated functionalities using the same $\mathrm{HNO}_{3}$ hydrothermal oxidation procedure. Kim et al. [Kim et al., 2006] have chemically treated carbon nanotubes using a mixture of $\mathrm{H}_{2} \mathrm{SO}_{4}$ and $\mathrm{HNO}_{3}$. The effects of acid treatment methods on the diameter dependent length separation of single walled carbon nanotubes were investigated. They found that smaller diameter nanotubes were preferentially shortened by the acid treatment process and migrated farther from the original sample well during the gel electrophoresis. This technique can provide a preparative, scalable method for separating nanotubes by length and diameter. Chiang et al [Chiang et al., 2011] also have investigated the influence of 
treatment duration on multi-walled carbon nanotubes functionalized by $\mathrm{H}_{2} \mathrm{SO}_{4} / \mathrm{HNO}_{3}$ oxidation. They found that if the samples were oxidized for two days they will had the most abundant surface - $\mathrm{COOH}$ and the highest oxidation resistance. The oxidation mechanism of MWNTs in mild $\mathrm{H}_{2} \mathrm{SO}_{4} / \mathrm{HNO}_{3}$ mixture was proposed, which was a successive and iterative process, including the initial attack on active sites, and next the hexagon electrophilic attack generating new defects and introducing more oxygen, and then the tubes becoming thinner and shorter.

Modification of carbon nanotubes by $\mathrm{KOH}$ or $\mathrm{NaOH}$ is a well-known method. MWNTs were modified by $\mathrm{KOH}$ in order to obtain high surface area with micropores. The adsorptiondesorption isotherms of $\mathrm{N}_{2}$ was applied to characterize the modified MWNTs. It was found that the specific surface area of MWNTs increases with increasing modification temperature of MWNTs, on the other hand, the average pore width decreases [Lee et al., 2005]. The capacity of hydrogen storage onto the $\mathrm{KOH}$ modified CNTs can be improved under ambient pressure and at moderate temperature [Chen \& Huang, 2007].

Raymundo-Piñero et al. [Raymundo-Piñero et al., 2005] obtained new information on the mechanism of porosity development during chemical activation by $\mathrm{KOH}$ and $\mathrm{NaOH}$ using various multiwalled nanotubes (MWNTs) of different structural organization. They show that $\mathrm{NaOH}$ is only effective with disordered materials whereas $\mathrm{KOH}$ is effective whatever the structural order. The nanotubular morphology is completely destroyed if the precursor reacted with $\mathrm{KOH}$ is in poor order, whereas it is preserved when $\mathrm{NaOH}$ is used. The morphology for the more ordered materials remains unchanged with both reactants. If $\mathrm{KOH}$ was used to activate the MWNTs a large concentration of defects in the nanotubes walls will generate. The differences found between $\mathrm{KOH}$ and $\mathrm{NaOH}$ during activation are related with an additional intercalation step of metallic $\mathrm{K}$ or Na produced during the redox reactions. It is shown that metallic $\mathrm{K}$ has the ability to be intercalated in all materials in contrast with $\mathrm{Na}$ which can only intercalate in the very disorganised ones.

Another reported method to functionalize SWNTs is solid-phase mechanochemical reaction in which potassium hydroxide $(\mathrm{KOH})$ reacted with SWNTs and hydroxyl groups were added directly onto the surfaces of SWNTs at room temperature [Pan et al., 2003]. However, when this technique was applied in treating MWNTs, the reactants $(\mathrm{KOH}$ and CNTs) agglomerated severely and could not mix equably. Our groups have presented a new way to modify the surfaces of pristine multi-walled carbon nanotubes (PCNTs) in a large scale production. We named this method as wet-mechanochemical reaction, in which PCNTs react with $\mathrm{KOH}$ in ethanol solvent at room temperature under mechanical milling. Compared with solid-phase mechanochemical reaction, the wetmechanochemical reaction, in addition to involving highly reactive centers generated by the mechanical energy imparted to the reaction system, makes materials contact effectively. Furthermore, compared with the CNTs from the acid treatment, the physical properties of the CNTs from the wet-mechanochemical reaction, such as the thermal conductivity applied in the nanofluids, will suffer minor effect [Chen et al., 2008a]. This method was successfully applied to functionalize SWNTs and double-walled carbon nanotubes (DWNTs). SWNTs and DWNTs with optimized aspect ratio can be obtained by adjusting the ball milling parameters [Chen \& Xie, 2010]. Mechanical ball milling following concentrated acid treatment is an effective means to obtain relatively straight CNTs with hydrophilic groups and an appropriate length distribution. The obtained CNTs wan used to prepare water and silicon oil based nanofluids, which has the optimized thermal conductivity enhancement. 


\section{Methods for CNT characterization}

Morphology of CNTs can be characterized by transmission electron microscopy (TEM) or scanning electron microscopy (SEM). The former one can give the structures of CNT walls, and the latter can exhibit the CNT outside sketch. UV-vis scanning spectra can be used to examine the fuctionalized CNTs to check the stability of the complex covalently attached to the CNTs and possible leaching of the complex. FT-IR spectroscopy can show that which kinds of groups are introduced on the CNT surfaces. X-ray diffraction (XRD) patterns of MWNTs can prove that if the modified MWNTs still have the same cylinder wall structure as raw MWNTs and inter-planner spacing of all samples remains the same. The mass loss given by the thermogravimetric analysis (TGA) also can show which groups grow on the CNT surfaces. Evidence for the modification of MWNTs coming from the XPS spectrum can reveal the surface chemical state, and can be used to calculate the content of elements on surface of MWNTs by area of each element. The weight content of elements can indicate the presence of groups [Salavati-Niasari \& Bazarganipour, 2008].

\section{Applications of carbon nanotubes as functional materials}

The possibility to combine the remarkable specificity and parallel processing of biomolecules with carbon nanotubes has attracted considerable attention for several types of applications, including the creation of new types of biosensors, the fabrication of drug or vaccine delivery devices, medical treatment, and so on. Furthermore, the functionalized carbon nanotubes can be also used in fuel cells, and in the field of thermal management.

Pantarotto et al. [Pantarotto et al., 2003] has shown that peptide-carbon nanotube complexes can enhance the immune (antibody) response against the peptides with no detectable crossreactivity to the carbon nanotubes. It has shown that the functionalized carbon nanotubes can cross cell membranes accumulate in the cytoplasm without being toxic for the cell. Zeng et al [Zeng et al., 2007] have successfully prepared novel CNT nano-composites by grafting poly(amidoamine) (PAMAM) with CNTs. The GOx and HRP immobilized CNT-PAMAM based on the functional CNTs was synthesized. The bi-enzymatic CNT-PAMAM nanocomposites are highly dispersible in water and show very promising applications in the fabrication of mediator-free bi-enzymatic biosensors for sensitive detection of glucose. The GOx and HRP immobilized CNT-PAMAM shows excellent performance for glucose sensing.

MWNTs can be fuctionalized using tetrahydrofuran solvent. THF is an oxygen-containing heterocycle with five-membered rings. The electronegativity difference between carbon and oxygen makes the $\mathrm{C}-\mathrm{O}$ bond moderately polar. Thus THF is a polar and aprotic solvent and has a sterically accessible oxygen atom. In chloroplantic acid solution THF could be protonated. Thus, $\mathrm{PtCl}_{6}{ }^{2-}$ and $\mathrm{Sn}^{4+}$ ions would be attracted to the sterically accessible oxygen atoms in THF by electrostatic self-assembly. Pt and binary $\mathrm{PtSn}$ nanoparticles can be synthesized on THF-functionalized MWNTs with high dispersion and uniform distribution due to their importance for the electrooxidation reactions of methanol and ethanol in low temperature fuel cells. PtSn/MWNTs show significantly lower onset potential and higher oxidation current densities toward the $\mathrm{CO}$ and ethanol electrooxidation as compared with pure $\mathrm{Pt} / \mathrm{MWNT}$ and conventional $\mathrm{Pt} / \mathrm{C}$ catalysts. The results demonstrated the effectiveness of the THF-functionalized MWNTs as the catalyst supports in the development of highly dispersed Pt and Pt-based electrocatalysts for low temperature fuel cells [Wang et al., 2010]. CNTs have been increasingly considered as an 
advanced metal catalyst support for proton exchange membrane fuel cells (PEMFCs), owing to their outstanding physical and mechanical characteristics [Saha \& Kundu, 2010]. Multi-walled carbon nanotubes have been functionalized by oxidation in acid medium and used as support for the incorporation of $\mathrm{Pt}$ nanoparticles. The $\mathrm{Pt}$ nanoparticles supported on the MWNTs subjected to the most severe functionalization treatment gives the best cathode electrode for PEMFC applications, even exceeding the performance of commercial $\mathrm{Pt} / \mathrm{C}$ commercial catalysts as the cathode electrode in a proton-exchange membrane fuel cell [Hernández-Fernández et al., 2010]. CNTs also can be effectively functionalized by intermittent microwave heating (IMH)-assisted $\mathrm{HF} / \mathrm{H}_{2} \mathrm{O}_{2}$ solution treatment. Pt supported on CNTs-HF/ $\mathrm{H}_{2} \mathrm{O}_{2}\left(\mathrm{Pt} / \mathrm{CNTs}-\mathrm{HF} / \mathrm{H}_{2} \mathrm{O}_{2}\right)$ has an average particle size of $2.8 \mathrm{~nm}$, smaller than that for Pt supported on CNTs treated by other methods. $\mathrm{Pt} / \mathrm{CNTs}-\mathrm{HF} / \mathrm{H}_{2} \mathrm{O}_{2}$ electrocatalysts display a high electrochemical surface area, high $\mathrm{Pt}$ utilization efficiency, a superior electrocatalytic and mass activity for the $\mathrm{O}_{2}$ reduction reaction (ORR) with respect to other catalyst samples. The obtained Pt/CNTs-HF/ $\mathrm{H}_{2} \mathrm{O}_{2}$ would be excellent electrocatalyst supports of fuel cells [Yin et al., 2009]. Reddy and Ramaprabhu [Reddy \& Ramaprabhu, 2007] have designed and developed a metal hydride-based hydrogen storage device. For the first time, good quality of MWNTs have been synthesized by pyrolysis of acetylene over hydrogen decrepitated alloy hydride catalyst. Pt-supported MWNTs (Pt/MWNTs) electrocatalysts have been prepared by chemical reduction method using functionalized MWNTs. Fabrications of a fuel cell stack and a planar configured microfuel cell have been done using membrane electrode assembly prepared with Pt/MWNTs electrocatalyst and Nafion 1135 membrane.

MWNTs have very high thermal conductivity, which make it excellent candidate to prepare thermal conductivity enhanced nanofluids. In our previous study, we developed some methods for preparing MWNT contained nanofluids. The nanofluids have the features of high thermal conductivity, long term stability, and surfactant-free. Briefly the present steps involved in the preparation of MWNT nanofluids include: (1) disentangle the nanotube aggregates and introduce hydrophilic functional groups on the surface of the nanotubes by mechanochemical reaction and (2) disperse the chemically treated MWNTs into a base fluid. Potassium hydroxide has been used to modify the surfaces of MWNTs. Distilled water (DW), ethylene glycol (EG), and glycerol (Gly) were used as base fluids. The aggregates and entanglements of PCNTs have been broken after chemical treatment. MWNTs were cut short by the intensive mechanical forces during the ball milling process. Thermal conductivity measurements revealed that the thermal conductivity enhancement reaches up to $17.5 \%$ at a volume fraction of 0.01 for an ethylene glycol based nanofluid and the temperature variation has no obvious effects on the thermal conductivity enhancement for the as prepared nanofluids [Chen et al., 2008b]. Surfactant-free nanofluids containing double- and single-walled carbon nanotubes were also obtained by using the same method. Study found that aspect ratios of the SWNTs and DWNTs could be tailored by adjusting the ball milling parameters. Chemical surface effects of CNTs play the main roles in improving the thermal conductivity enhancement with the increase of temperature. CNTs with smaller diameters offer more contribution to the thermal conductivity enhancement of CNT waterbased nanofluids compared with the CNTs with larger diameters. Thermal conductivity enhancement also has close relation to the initial heat transfer performance of the CNTs [Chen \& Xie, 2010a]. Another method was also applied in which MWNTs were treated by concentrated acid combined with mechanical ball mill technology. The treated multi-walled carbon nanotubes (TCNTs) with functionalized surfaces and controlled morphologies were 
used to prepare silicon oil based nanofluids by using hexamethyldisiloxane as dispersant. Thermal conductivity results of the obtained nanofluids show that the collective effects, involving straightness ratio, aspect ratio, and aggregation of TCNTs, play a key role in the thermal conductivity of CNT nanofluids. This study suggests that the thermal characteristics of nanofluids might be manipulated by means of controlling the morphology of the additions, which also provide a promising way to conduct investigation on the mechanism of heat transfer in nanofluids [Chen \& Xie, 2009]. Furthermore, stable homogeneous nanofluids of MWNTs were prepared by using gemini cationic surfactant trimethylene-1,3bis (dodecyldimethyl ammonium bromide), abbreviated as $12-3-12,2 \mathrm{Br}-1$, as dispersing agents. At relatively low temperatures the superfluous surfactant molecules form stable layer or column micelles, making an increase in the viscosity of nanofluids. Only $0.6 \mathrm{wt} \%$ gemini surfactant used to obtain $0.5 \mathrm{wt} \%$ MWNTdispersions. The dispersions show no MWNTs precipitation for at least 5 weeks [Chen et al., 2008c]. Another research shows that higher concentration of cationic gemini surfactant is a negative factor in improving the thermal conductivity of nanofluids. Increase of spacer chain length of cationic Gemini surfactant gives rise to the sediment of MWNTs in the nanofluids, resulting in decrease of thermal conductivity enhancement of MWNT nanofluids [Chen \& Xie, 2010b].

\section{Conclusion}

Many potential applications of carbon nanotubes often need them to be prior purified and functionalized. Some effective methods to functionalize carbon nanotube surfaces including covalent modification, noncovalent approaches, chemical and solid-phase, hydromechanochemical method, and so on have been summarized. The advantages and shortcomings of the functionalization method were also showed clarified. At the same time some characterization ways for carbon nanotubes were refered. In the last part of this chapter the applications of carbon nanotubes as functional materials in the fields of biosensing, fuel cells, medical treatment, and so on, especially in the field of thermal management are summarized. It is our hope that all the content of this chapter can supply helps to the researchers in the field of carbon nanotubes.

\section{Acknowledgments}

This work was supported by the Program for Professor of Special Appointment (Eastern Scholar) at Shanghai Institutions of Higher Learning, and the Program for New Century Excellent Talents in University (NCET-10-883).

\section{References}

Ayala, P., Grüuneis, A., Kramberger, C., Grimm, D., Engelhard, R., Rüummeli, M.H., Schumann, J., Kaltofen, R., Büuchner, B., Schaman, C., Kuzmany, H., Gemming, T., Barreiro, A., \& Pichler, T. (2008). Cyclohexane triggers staged growth of pure and vertically aligned single wall carbon nanotubes. Chemical Physics Letters, Vol. 454, No. 4-6,(March 2008), pp.332-336, ISSN 0009-2614

Baker,S.E., Cai, W., Lasseter, T.L., Weidkamp, K.P., \& Hamers, R.J. (2002). Covalently bonded adducts of deoxyribonucleic acid (DNA) oligonucleotides with single-wall 
carbon nanotubes Synthesis and hybridization. Nano letters, Vol.2, No.12,(October 2002), pp.1413-1417, ISSN 1530-6984

Balasubramanian, K., \& Burghard, M. (2005). Chemically functionalized carbon nanotubes. Small, Vol.1,(January 2005), pp.180-192, ISSN 1613-6810

Bale, S.S., Asuri, P., Karajanagi, S.S., Dordick, J.S., \& Kane, R.S. (2007). Protein directed formation of silver nanoparticles on carbon nanotubes. Advanced Materials, Vol.19, No.20, (October 2007), pp. 3167-3170, ISSN 1521-4095

Bianco, A., Kostarelos, K., \& Prato, M. (2005). Applications of carbon nanotubes in drug delivery. Current Opinion in Chemical Biology, Vol. 9,No.6, (December 2005), pp.674679, ISSN 1367-5931

Bystrzejewski, M., Rümmeli, M.H., Lange, H., Huczko, A., Baranowski, P., Gemming, T., \& Pichler, T. (2008). Single-walled carbon nanotubes synthesis a direct comparison of laser ablation and carbon arc routes. Journal of Nanoscience and Nanotechnology, Vol.8, No.1, (January 2008), pp.6178-6186(9), ISSN 1550-7033

Chen, C.H., \& Huang, C.C. (2007). Hydrogen storage byKOH-modified multi-walled carbon nanotubes. International Journal of Hydrogen Energy, Vol.32, No.2, (February 2007), pp.237-246, ISSN 0360-3199

Chen, L.F., Xie, H.Q., Li, Y., \& Yu, W. (2008a) Surface ChemicalModification of Multiwalled Carbon Nanotubes by aWet-Mechanochemical Reaction. Journal of Nanomaterials, Article ID 783981, 5 pages

Chen, L.F., \& Xie, H.Q. (2010a). Surfactant-free nanofluids containing double- and singlewalled carbon nanotubes functionalized by a wet-mechanochemical reaction. Thermochimica Acta, Vol.497, No.1-2, (October 2007), pp. 67-71, ISSN 0040-6031

Chen, L.F., \& Xie, H.Q. (2009). Silicon oil based multiwalled carbon nanotubes nanofluid with optimized hermal conductivity enhancement. Colloids and Surfaces A, Vol.352, No.1-3, (December 2009), pp.136-140, ISSN 0927-7757

Chen, L.F., Xie, H.Q., Li, Y., \& Yu, W. (2008b). Nanofluids containing carbon nanotubes treated by mechanochemical reaction. Thermochimica Acta, (October 2008),Vol.477, No.1-2, pp.21-24, ISSN 0040-6031

Chen, L.F., Xie, H.Q., Li, Y., \& Yu, W. (2008c). Applications of cationic gemini surfactant in preparing multi-walled carbon nanotube contained nanofluids. Colloids and Surfaces A,

Vol.330, No.2-3,(December 2008), pp.176-179, ISSN 0927-7757

Chen, L.F., \& Xie, H.Q. (2010b). Properties of carbon nanotube nanofluids stabilized by cationic gemini surfactant. Thermochimica Acta, Vol. 50, No. 1-2, (July 2010), pp.6266, ISSN 0040-6031

Chiang, Y.C., Lin, W.H, \& Chang, Y.C. (2011). The influence of treatment duration on multiwalled carbon nanotubes functionalized by $\mathrm{H} 2 \mathrm{SO} 4 / \mathrm{HNO} 3$ oxidation. Applied Surface Science, Vol.257, No.6, (Junauary 2011), pp. 2401-2410, ISSN 0169-4332

Angiolini, L., Benelli, T., Giorgini, L.,\& Salatelli, E.(2006). Optically active photochromic polymers with three-arm star structure by atom transfer radical polymerization, Macromolecules, Vol.39, No.5,(May 2006), pp. 3731-3737, ISSN 0024-9297

Greaves, T.L., \& Drummond, C.J. (2008). Protic Ionic Liquids Properties and Applications. Chemical Reviews., Vol.108, No.1,(December 2007), pp. 206-237, ISSN 0009-2665 
Hazani, M., Naaman, R., Hennrich, F., \& Kappes, M.M. (2003). Confocal fluorescence imaging of DNA-functionalized carbon nanotubes, Nano letters, Vol.3, No.2, (December 2002), pp.153-155, ISSN 1530-6984

Hektor, H.J., \& Scholtmeijer, K., (2005). Hydrophobins proteins with potential. Current Opinion in Biotechnology, Vol.16, No.4, (August 2005), pp.434-439, ISSN 1367-5931

Hernández-Fernández, P., Montiel, M., Ocón, P., Gómez de la Fuente, J.L., GarcíaRodríguez, S., Rojas, S., \& Fierro, J.L.G. (2010). Functionalization of multi-walled carbon nanotubes and application as supports for electrocatalysts in protonexchange membrane fuel cell. Applied Catalysis B Environmental, Vol.99, No.12,(August 2010), pp. 343-352, ISSN 0926-3373

Hu, C.G., Chen, Z.L., Shen, A.G., Shen, X.C., Li, J., \& Hu, S.S. (2006). Water-soluble singlewalled carbon nanotubes via noncovalent functionalization by a rigid, planar and conjugated diazo dye. Carbon, Vol.44, No.3, (March 2006), pp. 428-434, ISSN 00086223

Huang, W., Taylor, S., \& Fu, K. (2002). Attaching proteins to carbon nanotubes via diimide activated amidation. Nano letters, Vol.2, No.4,(March 2002), pp.311-314, ISSN 15306984

Iijima, S. (1991) Helical microtubules of graphitic carbon. Nature, Vol. 354, (November 1991), pp. 56-58.

Kim, Y., Lee, D., Oh, Y., Choi, J., \& Baik, S. (2006). The effects of acid treatment methods on the diameter dependent length separation of single walled carbon nanotubes. Synthetic Metals, Vol.156, No.16-17, (August 2006), pp.999-1003, ISSN 0379-6779

Lee Mohana Reddy, A., \& Ramaprabhu, S. (2007). Design and fabrication of carbon nanotube-based microfuel cell and fuel cell stack coupled with hydrogen storage device. International Journal of Hydrogen Energy, Vol.32, No.17, (December 2007), pp.4272-4278, ISSN 0360-3199

Lee, S.M., Lee, S.C., Jung J.H., \& Kim, H.J. (2005). Pore characterization of multi-walled carbon nanotubes modified by $\mathrm{KOH}$. Chemical Physics Letters, Vol.416, No.4-6, (December 2005), pp.251-255, ISSN 0009-2614

Li, C.Y., Li, L.Y., Cai, W.W., Kodjie, S.L., \& Tenneti, K.K. (2005). Nanohybrid Shish-kebabs periodically functionalized carbon nanotubes. Advanced Materials,Vol.17, No.9, (May 2005), pp.1198-202, ISSN 1521-4095

Li, L., \& Xing, Y. (2007). Pt-Ru Nanoparticles Supported on Carbon Nanotubes as Methanol Fuel Cell Catalysts. Journal of Physical Chemistry C, Vol.111, No.6, (January 2007), pp. 2803-2808, ISSN 1932-7447

Li ,L.Y., Li, C.Y., \& Ni, C.Y. (2006). Polymer crystallization-driven, periodic patterning on carbon nanotubes. Journal of the American Chemical Society, Vol.128, No.5, (January 2006) pp.1692-1699, ISSN 0002-7863

Li, X., Wong, S.Y., Tjiu, W.C., Lyons, B.P., Oh, S.A., \& He, C.B. (2008). Non-covalent functionalization of multi walled carbon nanotubes and their application for conductive composites. Carbon, Vol.46, No.5, (April 2008), pp.829-831, ISSN 00086223 
Li, Z.Z., Wu, Z.Y., \& Li, K. (2009). The high dispersion of DNA-multiwalled carbon nanotubes and their properties. Analytical Biochemistry, Vol. 387, No.2, (April 2009), pp.267-270, ISSN 0003-2697

Liu, C.H., Li, J.J., Zhang, H.L., Li, B.R., \& Guo, Y. (2008). Structure dependent interaction between organic dyes and carbon nanotubes. Colloids and Surfaces A, Vol.313-314, No.1, (February 2008), pp.9-12, ISSN 0927-7757

Liu, Y.T., Zhao, W., Huang, Z.Y., Gao, Y.F., Xie, X.M., Wang, X.H., \& Ye, X.Y. (2006). Noncovalent surface modification of carbon nanotubes for solubility in organic solvents. Letters to the Editor / Carbon, Vol.44, No.8, (July 2006), pp.1613-1616, ISSN 0008-6223

Liu, Z., Winters, M., Holodniy, M., Dai, H.J. (2007). siRNA delivery into human T cells and primary cells with carbon-nanotube transporters, Angewandte Chemie International Edition, Vol.46, No.12,(March 2007), pp.2023-2027,ISSN 1521-3773

Lu, Y., Bangsaruntip, S., Wang, X., Zhang, L., Nishi, Y., \& Dai, H. (2006). DNA functionalization of carbon nanotubes for ultrathin atomic layer deposition of high kappa dielectrics for nanotube transistors with $60 \mathrm{mV} /$ decade switching, Journal of the American Chemical Society, Vol.128, No.11, (March 2006), pp.3518-3519, ISSN 0002-7863

Lustig, S.R., Jagota, A., Khripin, C., \& Zheng, M. (2005). Theory of structure-based carbon nanotube separations by ion-exchange chromatography of DNA/CNT hybrids, Journal of Physical Chemistry B, Vol.109, No.7,(January 2005), pp.2559-2566, ISSN 1520-6106

Marques, R.R.N., Machado, B.F., Faria, J.L., \& Silva, A.M.T. (2010). Controlled generation of oxygen functionalities on the surface of Single-Walled Carbon Nanotubes by HNO3 hydrothermal oxidation. Carbon, Vol.48, No.5,(April 2010), pp.1515-1523, ISSN 0008-6223

Maruyama, H., Yoshimura, S. H., \& Akita, S. (2007). Covalent attachment of protein to the tip of a multiwalled carbon nanotube without sidewall decoration. Journal of Applied Physics, Vol.102, No.9, (November 2007), pp. 094701-094705,ISSN 0021-8979

McQuade, D.T., Pullen, A.E., \& Swager, T.M. (2000). Conjugated Polymer-Based Chemical Sensors.Chemical Reviews, Vol.100, No.7, (June 2000), pp.2537-2574, ISSN 0009-2665

Mohana Reddy, A.L., Rajalakshmi, N., \& Ramaprabhu, S. (2008). Cobalt-polypyrrolemultiwalled carbon nanotube catalysts for hydrogen and alcohol fuel cells. Carbon, Vol.46, No.1, (January 2008), pp. 2-11, ISSN 0008-6223

Moniruzzaman, M., \&Winey, K.I. (2006). Polymer nanocomposites containing carbon nanotubes. Macromolecules, Vol. 39, No.16, (July 2006), pp.5194-5205, ISSN 00249297

Moulton, S. E., Minett, A.I., Murphy, R., Ryan, K.P., McCarthy, D., Coleman, J.N., Blau, W.J., \& Wallace, G.G. (2005). Biomolecules as selective dispersants for carbon nanotubes. Carbon, Vol. 43, No.9,(August 2005), pp.1879-1884, ISSN 0008-6223

Nikolaev, P., Bronikowski, M.J., Bradley, R.K., Rohmund, F., Colbert, D.T., Smith, K.A., \& Smalley, R.E. (1999). Gas-phase catalytic growth of single-walled carbon nanotubes from carbon monoxide. Chemical Physics Letters, Vol.313, No. 1-2,(November 1999), pp. 91-97, ISSN 0009-2614 
Pan, H. L., Liu, L. Q., Guo, Z. X., Dai, L. M., Zhang, F.S., \& Zhu, D. B. (2003). Carbon Nanotubols from Mechanochemical Reaction. Nano letters, Vol.3, No.1, (November 2002), pp. 29-32, ISSN 1530-6984

Pantarotto, D., Partidos, C.D., Graff, R., Hoebeke, J., Briand, J.P., \& Prato, M. (2003). Synthesis, structural characterization, and immunological properties of carbon nanotubes functionalized with peptides. Journal of the American Chemical Society, Vol.125, No.20, (April 2003), pp. 6160-6164, ISSN 0002-7863

Park, C., Lee, S., Lee, J.H., Lim, J., Lee, S.C., Park, M., Lee, S. S., Kim, J., Park, C.R., \& Kim. C. (2007). Controlled assembly of carbon nanotubes encapsulated with amphiphilic block copolymer. Carbon, Vol.45, No.10,(September 2007), pp.2072-2078, ISSN 00086223

Peng, F.B., Pan, F.S., Sun, H.L., Lu, L.Y., \& Jiang, Z.Y. (2007). Novel nanocomposite pervaporation membranes composed of poly(vinyl alcohol) and chitosan-wrapped carbon nanotube. Journal of Membrane Science, Vol.300, No.1-3,(August 2007), pp.1319, ISSN 0376-7388

Peng, S., \& Cho, K. (2000). Chemical control of nanotube electronics. Nanotechnology, Vol.11, No.2, (June 2000), pp.57-60, ISSN 0957-4484

Raymundo-Piñero, E., Azaïs ,P., Cacciaguerra, T., Cazorla-Amoró s, D., Linares-Solano, A., \& Béguin, F. (2005). $\mathrm{KOH}$ and $\mathrm{NaOH}$ activation mechanisms of multiwalled carbon nanotubes with different structural organization. Carbon, Vol.43, No.4, (April 2005) pp.786-795, ISSN 0008-6223

Rümmeli, M.H., Kramberger, C., Loeffler, M., Jost, O.,Bystrzejewski, M., Grueneis, A., Gemming, T., Pompe, W., Buechner, B., \& Pichler, T. (2007). Catalyst volume to surface area constraints for nucleating carbon nanotubes. Journal of Physical Chemistry B, Vol. 111, No. 28, (June 2007),pp. 8234-8241, ISSN 1520-6106

Saha, M.S., \& Kundu, A. (2010). Functionalizing carbon nanotubes for proton exchange membrane fuel cells Electrode. Journal of Power Sources, Vol.195, No.19, (October 2010), pp.6255-6261, ISSN 0378-7753

Salavati-Niasari, M., \& Bazarganipour, M. (2008). Covalent functionalization of multi-wall carbon nanotubes (MWNTs) by nickel(II) Schiff-base complex Synthesis, characterization and liquid phase oxidation of phenol with hydrogen peroxide. Applied Surface Science, Vol.255, No.5, (December 2008),pp.2963-2970, ISSN 01694332

Sluzarenko, N., Heurtefeu, B., Maugey, M., Zakri, C., Poulin, P., \& Lecommandoux, S. (2006). Diblock copolymer stabilization of multi-wall carbon nanotubes in organic solvents and their use in composites. Carbon, Vol.44, No.15, (December 2006), pp.3207-3212, ISSN 0008-6223

Sun, X., Bao,W., Lv,Y., Deng, J., \& Wang, X. (2007). Synthesis of high quality singlewalled carbon nanotubes by arc discharge method in large scale. Material Letter, Vol. 61, No. 18, (July 2007), pp. 3956-3958, ISSN 0167-577X

Sung, J.H., Kim, H.S., Jin, H.-J., Choi, H.J., \& Chin, I.-J. (2004). Nanofibrous membranes prepared by multiwalled carbon nanotube/poly(methylmethacrylate) composites, Macromolecules, Vol.37, No.26, (December 2004), pp.9899-9902, ISSN 0024-9297 
Szleifer, I., \& Yerushalmi-Rozen, R. (2005). Polymers and carbon nanotubes dimensionality, interactions and nanotechnology. Polymer, Vol.46, No.19,(September 2005), pp.7803-7818, ISSN 0032-3861

Thess, A., Lee, R., Nikolaev, P., Dai, H., Petit, P., Robert, J., Xu, C., Lee, Y.H., Kim, S.G., Tournus, F., Latil, S., Heggie, M.I., \& Charlier, J.C. (2005). п-stacking interaction between carbon nanotubes and organic molecules. Physical Review B Condensed Matter, Vol.72, (August 2005), pp. 075431, ISSN 1098-0121

van Wetter, M.A., WÖten, H.A.B., \& Wessels, J.G.H. (2000). SC3 and SC4 hydrophobins have distinct roles in formation of aerial structures in dikaryons of Schizophyllum commune. Molecular Microbiology, Vol.36, No.1, (January 2000), pp. 201-210, ISBN 978-0-12-677530-3

Vigolo, B., Mamane, V., Valsaque, F., Ha Le, T.N., Thabit, J., Ghanbaja, J., Aranda, L., Fort, Y., \& McRae, E. (2009). Evidence of sidewall covalent functionalization of singlewalled carbon nanotubes and its advantages for composite processing. Carbon, Vol.47, No.2, (February 2009), pp.411-419, ISSN 0008-6223

Waghuley, S.A., Yenorkar, S.M., Yawale, S.S., \& Yawale, S.P. (2008). Application of chemically synthesized conducting polymer-polypyrrole as a carbon dioxide gas sensor. Sensors and Actuators, B, Vol.128, No.2, (January 2008), pp.366-373, ISSN 0925-4005

Wang, W.R., Xie, X.M., \&Ye, X.Y. ( 2010). Crystallization induced block copolymer decoration on carbon nanotubes. Carbon, Vol.48, No.5,(April 2010), pp.1680-1683, ISSN 0008-6223

Wang, X. S., Wang, H.C., Huang, Y.J., Zhao, Z.X., Qin, X., Wang, Y.Y., Miao, Z.Y., Chen,Q., \& Qiao, M.Q. (2010). Noncovalently functionalized multi-wall carbon nanotubes in aqueous solution using the hydrophobin HFBI and their electroanalytical application. Biosensors and Bioelectronics, Vol.26, No.3, (November 2010), pp.11041108, ISSN 09565663

Wang, Y., Iqbal, Z., \& Mitra, S. (2006). Rapidly Functionalized, Water-Dispersed Carbon Nanotubes at High Concentration. Journal of the American Chemical Society, Vol.128, No.1, (December 2005), pp.95-99, ISSN 0002-7863

Wei, G., Pan, C.J., Reichert, J., \& Jandt ,K.D. (2010). Controlled assembly of protein-protected gold nanoparticles on noncovalent functionalized carbon nanotubes. Carbon, Vol.48, No.3, (January 2011), pp.645-653, ISSN 0008-6223

Williams, K. A., Veenhuizen, P. T. M., \& de la Torre, B.G.R. (2002). Nanotechnology Carbon nanotubes with DNA recognition. Nature,Vol.420, (December 2002), pp.761-761

Woo, S.-W., Dokko, K., \& Kanamura, K. (2008). Composite electrode composed of bimodal porous carbon and polypyrrole for electrochemical capacitors. Journal of Power Sources, Vol.185, No.2, (December 2008), pp.1589-1593, ISSN 0378-7753

Wu, W., Wieckowski, S., \& Pastorin, G. (2005). Targeted delivery of amphotericin B to cells by using functionalized carbon nanotubes. Angewandte Chemie International Edition, Vol.44,No.39,(October 2005), pp.6358-6362,ISSN 1521-3773

Xu, G.D., Zhu, B., Han, Y., \& Bo, Z.S. (2007). Covalent functionalization of multi-walled carbon nanotube surfaces by conjugated polyfluorenes. Polymer, Vol. 48, No. 26,(December 2007), pp. 7510-7515, ISSN 0032-3861 
Xue, Y.D., Bao, L., Xiao, X.R., Ding, L., Lei, J.P., \& Ju. H.X. (2011). Noncovalent functionalization of carbon nanotubes with lectin for label-free dynamic monitoring of cell-surface glycan expression. Analytical Biochemistry, Vol.410, No.1, (March 2011), pp.92-97, ISSN 0003-2697

Yang, Y.K., Qiu, S.Q. He, C.G., He, W.J., Yu, L.J., \& Xie, X.L. (2010). Green chemical functionalization of multiwalled carbon nanotubes with polyin ionic liquids. Applied Surface Science, Vol.257, No. 3, (November 2010), pp. 1010-1014, ISSN 01694332

Yin, S.B., Shen, P.K., Song, S.Q., \& Jiang, S.P. (2009), Functionalization of carbon nanotubes by an effective intermittent microwave heating-assisted $\mathrm{HF} / \mathrm{H} 2 \mathrm{O} 2$ treatment for electrocatalyst support of fuel cells. Electrochimica Acta, Vol.54, No.27, (November 2009),pp.6954-6958, ISSN 0013-4686

Zhao, Y. C., Yang, X.L., Tian,J.N., Wang, F.Y., \& Zhan, L. (2010). A facile and novel approach toward synthetic polypyrrole oligomers functionalization of multi-walled carbon nanotubes as PtRu catalyst support for methanol electro-oxidation. Journal of Power Sources, Vol.195, No.15, (August 2010), pp. 4634-4640, ISSN 0378-7753

Zeng, H., Gao, C., \& Yan, D. (2006). Poly( $\varepsilon$-caprolactone)-Functionalized Carbon Nanotubes and Their Biodegradation Properties. Advanced Functional Materials, Vol.16, No.6,(February 2006), pp. 812-818, ISSN 1616-3028

Zeng, Y.L., Huang, Y.F., Jiang, J.H., Zhang, X.B., Tang, C.R., Shen, G.L., \& Yu, R.Q. (2007). Functionalization of multi-walled carbon nanotubes with poly(amidoamine) dendrimer for mediator-free glucose biosensor. Electrochemistry Communications, Vol.9, No.1, (January 2007) pp.185-190, ISSN 388-2481

Zhang, Y.J., Wen, Y., Liu, Y., Li, D., \& Li, J.H. (2004). Functionalization of single-walled carbon nanotubes with Prussian blue. Electrochemistry Communications, Vol.6, No.11, (November 2004), pp.1180-1184, ISSN 1388-2481

Zhang, Z.N., Zhang, J., Chen, P., Zhang, B.Q., He, J.S., \& Hu, G.H. (2006). Enhanced interactions between multi-walled carbon nanotubes and polystyrene induced by melt mixing. Carbon, Vol.44, No.4, (April 2006), pp.692-698, ISSN 0008-6223

Zhao, J., Lu, J.P., Han, J., \& Yang, C.-K. (2003). Noncovalent functionalization of carbon nanotubes by aromatic organic molecules, Applied Physics Letters, Vol.82, No.21 (April 2003), pp.3746-3748, ISSN 0003-6951

Zheng, M., Jagota, A., Semke, E.D., Diner, B.A., McLean, R.S., \& Lustig, S.R. (2003). DNAassisted dispersion and separation of carbon nanotubes. Nature-Materials, Vol.2, No.5, (April 2003), pp. 338-342

Zhong, J., Song, L., Meng, J., Gao, B., Chu, W.S., Xu, H.Y., Luo, Y., Guo, J.H., Marcelli, A., Xie, S.S., \& Wu. Z.Y. (2009). Bio-nano interaction of proteins adsorbed on singlewalled carbon nanotubes. Carbon, Vol.47, No.4, (April 2009)pp.967-973, ISSN 00086223

Zou, J.H., Liu, L.W., Chen, H., Khondaker, S.I., McCullough, R.D., \& Huo, Q. (2008). Dispersion of pristine carbon nanotubes using conjugated block copolymers. Advanced Materials, Vol.20, No.11, (June 2008), pp.2055-2060, ISSN 1521-4095 


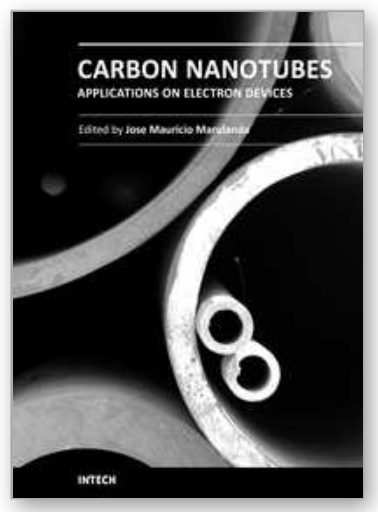

\section{Carbon Nanotubes Applications on Electron Devices}

Edited by Prof. Jose Mauricio Marulanda

ISBN 978-953-307-496-2

Hard cover, 556 pages

Publisher InTech

Published online 01, August, 2011

Published in print edition August, 2011

Carbon nanotubes (CNTs), discovered in 1991, have been a subject of intensive research for a wide range of applications. In the past decades, although carbon nanotubes have undergone massive research, considering the success of silicon, it has, nonetheless, been difficult to appreciate the potential influence of carbon nanotubes in current technology. The main objective of this book is therefore to give a wide variety of possible applications of carbon nanotubes in many industries related to electron device technology. This should allow the user to better appreciate the potential of these innovating nanometer sized materials. Readers of this book should have a good background on electron devices and semiconductor device physics as this book presents excellent results on possible device applications of carbon nanotubes. This book begins with an analysis on fabrication techniques, followed by a study on current models, and it presents a significant amount of work on different devices and applications available to current technology.

\section{How to reference}

In order to correctly reference this scholarly work, feel free to copy and paste the following:

Lifei Chen, Huaqing Xie and Wei Yu (2011). Functionalization Methods of Carbon Nanotubes and Its Applications, Carbon Nanotubes Applications on Electron Devices, Prof. Jose Mauricio Marulanda (Ed.), ISBN: 978-953-307-496-2, InTech, Available from: http://www.intechopen.com/books/carbon-nanotubes-applicationson-electron-devices/functionalization-methods-of-carbon-nanotubes-and-its-applications

\section{INTECH}

open science | open minds

\section{InTech Europe}

University Campus STeP Ri

Slavka Krautzeka 83/A

51000 Rijeka, Croatia

Phone: +385 (51) 770447

Fax: +385 (51) 686166

www.intechopen.com

\section{InTech China}

Unit 405, Office Block, Hotel Equatorial Shanghai

No.65, Yan An Road (West), Shanghai, 200040, China 中国上海市延安西路65号上海国际贵都大饭店办公楼 405 单元

Phone: +86-21-62489820

Fax: $+86-21-62489821$ 
(C) 2011 The Author(s). Licensee IntechOpen. This chapter is distributed under the terms of the Creative Commons Attribution-NonCommercialShareAlike-3.0 License, which permits use, distribution and reproduction for non-commercial purposes, provided the original is properly cited and derivative works building on this content are distributed under the same license. 